\title{
System and State in International Politics: A Computer Simulation of Balancing in an Anarchic World
}

\author{
RichaRd J. STOLL \\ Rice University
}

\begin{abstract}
The relationship between state behavior and system behavior has occupied the attention of scholars and practitioners of international politics for hundreds of years. The predominant assumption of state behavior is that states act in their self-interest; this is their best guarantee of survival in an anarchic world. But most observers feel that system equilibrium is not possible in a world of such states; some additional element is necessary to preserve the main characteristics of the system. In this paper, a computer simulation is used to investigate (a) whether in a world of self-interested states, system-level behavior that acts to preserve or restore equilibrium will emerge, and (b) whether this is sufficient to preserve most of the actors in the system.
\end{abstract}

\section{Introduction}

For hundreds of years scholars and practitioners of international politics have studied and written about the interrelationship between the actions of individual states and the behavior of the interstate system. Two questions have been of particular concern: (1) how do states interact to create or modify the system? and (2) how does the system constrain the actions of individual states? In this paper I will use a computer simulation to explore whether in a particular anarchic system, the interaction of self-interested states can lead to emergent properties above the state level, and whether in turn, these properties can serve to preserve the essential characteristics of the state system.

\section{Preserving the State and Preserving the System in an Anarchic World}

In the writings of many, the interstate system is viewed as an anarchy. There are few rules of conduct between states, and no supranational actor to enforce any code of behavior. As a result, international politics is a "struggle for power."

\footnotetext{
Author's note: My thanks to the editors and reviewers at $I S Q$ for their suggestions and their patience. This paper is
} much improved owing to their efforts. Of course, any errors are mine and mine alone.

0020-8833/87/04 0387-16 \$03.00 @ 1987 International Studies Association 


\section{Preserving the State}

One popular theme in the international politics literature is the implication of an anarchic world for individual states. They must use every means at their disposal to protect, preserve, and expand their interests. Of course, states must not behave recklessly; expansion in the face of more powerful adversaries can result in defeat, with its attendant loss of power. It may even result in the elimination of the state. The notion that a successful state is one that prudently exercises power to advance its interests is widely held by such diverse authors as the "policy advisors" Kautilya and Machiavelli (Modelski, 1964; Machiavelli, 1940), the realist school that developed in the early post-World War II era (Morganthau, revised by Thompson, 1985), and scholars who combine formal deductive models with statistical tests (Bueno de Mesquita, 1981).

This list is by no means a complete one, but demonstrates that a wide variety of authors have worked within this framework. All assume that "reason of state" is the only justification necessary for a government to undertake actions, no matter what the consequences for other states. All authors share an interest in predicting and understanding the maneuvers of individual states in an anarchic environment.

\section{Preserving the System}

Another popular theme in international politics discussed by many authors (including some of those just mentioned) is the behavior of the system. Interest in this topic springs from many sources, but surely one is the apparently paradoxical observation that while individual states are assumed to pursue their interests, even if this means destroying other states, there are large blocks of time during which all the prominent states in a system survive relatively intact. How does a system whose members are individually committed to expansion maintain itself in equilibrium? This is a key question in the vast and tangled literature on the "balance of power" (see Haas, 1953; and Claude, 1962, for surveys of the multiple meanings that have been attached to this phrase).

The literature suggests a number of different answers to that question. One is that in a balance-of-power system, there are certain rules of behavior that among other things proscribe the elimination of at least the prominent states. States are free to pursue their interests, even if this requires the waging of war, but they cannot take the final step of destroying an opponent-at least not an essential one (Kaplan, 1957: 22-36).

A second answer to the question is the existence within the system of a small number of states (usually one) that maintain a strong interest in the equilibrium of the system, and act to preserve it. Such states are called balancers; Great Britain is often asserted to have played this role for many years in the European state system (Crowe, 1929; reprinted in Pfaltzgraff, 1971).

A third answer to how the system is preserved assumes that in a balance-of-power system, power is distributed fairly evenly across the major states of the system, and that these states have a large number of short-term ties to other members of the system. This combination makes it almost impossible for a state to estimate accurately the consequences of any aggressive actions (Deutsch and Singer, 1964; Singer, Bremer, and Stuckey, 1972). Prudence therefore dictates that a state should refrain from engaging in expansionist activity because of the possible losses that may result. 


\section{The "Invisible Hand" and the Preservation of the System}

Although each of these answers is very different, they all do share a common element. Each assumes that something beyond the self-interest of states is necessary to maintain or restore system equilibrium. This additional element can take the form of a unique kind of state (a balancer); it can involve a feature of the international regime (rules prohibiting the destruction of states); or it might be found in a particular start-up condition (the even distribution of power); but the presumption is that if this element should disappear, the system is likely to undergo some fundamental transformation.

Not everyone agrees that some special stabilizing element is necessary to preserve or restore equilibrium. In his typology of balance-of-power systems (a system defined as a certain kind of arrangement for the operation of international relations in a world of many states), Claude (1962: 20-25) discusses an automatic balance-ofpower system. In such a system, the cumulative effect of all states pursuing their self-interest is the preservation of equilibrium. The principle is analogous to that of the "invisible hand" in economics; all buyers and sellers are assumed to maximize their self-interest, but the result at the system level is that without conscious motivation or even awareness on the part of any individual actor, equilibrium of supply and demand is maintained.

The most forceful contemporary advocate of the ability of an automatic balanceof-power system to stabilize itself is Waltz $(1975,1979)$. To him, "[b]alance of power theory is a theory about the results produced by the uncoordinated action of individual states. It is not a theory of state policy, but rather a theory about environmental constraints. The environment is produced by the actions and the interactions of states, but that environment then appears, like a market in a competitive economy, as a force that no state acting alone can control (Waltz, 1975: 41)."

Despite Waltz's assertive statement, he is very much in the minority. The opinion of the majority is certainly that we should not expect states to rise above self-interest in their individual actions; indeed, a state that fails to recognize and act on this basis courts disaster. But while assuming that self-interest is the only reliable guide to state survival, the majority views it as an insufficient guarantee of system stability.

But there are several reasons we should not be so quick to pass off the impact of the interaction of a group of self-interested states. First, in a system in which most states pursue their own self-interest, the resulting interaction may be so powerful as to overwhelm the various mechanisms that are counted on to maintain equilibrium. Certainly, in the economic sphere any number of examples, from the existence of black markets in Communist countries to the troubles of the Organization of Petroleum Exporting Countries in times of lowered demand for oil, demonstrate that individual self-interest is a powerful force that can be only partly restrained by nonmarket means.

Second, the interaction of self-interested actors may have positive effects, as demonstrated in the recent work of Axelrod (1984). He shows that in a wide variety of settings cooperation can emerge and persist in social systems that consist entirely of egoists (actors motivated by self-interest), without any central authority. Axelrod's research does not show that self-interest always leads to a cooperative outcome, but he does demonstrate that this outcome can occur in a variety of unlikely circumstances. 
Consequently, we have reason to suspect that self-interest produces powerful effects, and ones that are not necessarily negative for the equilibrium of the system. These suspicions deserve closer investigation in the arena of international relations theory, and lie at the heart of this paper. More specifically I will explore whether in a primitive, anarchic system in which all states base their decisions on a simple calculation of power gain and loss, (a) does system-preserving (i.e., balancing) behavior emerge? and (b) is this sufficient to preserve the existence of a multistate system?

My exploration is conducted by analyzing data generated by a Monte Carlo computer simulation. The program is a reconstruction of a simulation developed a decade ago (Bremer and Mihalka, 1977), which unfortunately no longer exists in its original form. Before I describe the program and the research design used to investigate the questions posed above, a short discussion on the value of computer simulation for this investigation is in order.

\section{The Merits of This Exercise}

Scholars of power politics and the balance of power have used a wide variety of methods in their research. Each has its own strengths and weaknesses, and all have yielded interesting conjectures and insights on the subject. My purpose here is not to review the techniques of others, but to argue that computer simulation can be a useful tool in exploring questions relating to power politics and the balance of power.

First let me be clear about the purpose of this paper. It is to conduct a "theoretical experiment." That is, I wish to explore certain long-run consequences of a set of assumptions about state behavior. For the present, I am not interested in whether the assumptions or their possible consequences mirror the actual behavior of states. In the long run, of course, it is the actual behavior of states and systems that is to be explained. But given the divergence in the theoretical literature as to the nature and existence of system equilibrium in an anarchic system, additional study at this level is merited.

Justifying this type of study is a two-part process. First, the case must be made for the value of abstract models as an aid to theory development. Second, the advantages of computer simulation in building and examining these models must be shown.

\section{The Value of Abstraction}

In a recent book, Gilpin (1981: xiii) discusses what he calls the basic dilemma of social science: to "explain trivial matters with exactitude, or to treat significant matters with imprecision." Despite the hyperbole, there is a certain amount of truth in his statement; and clearly, this paper falls into the latter of Gilpin's two categories. What is the value of such studies?

Their primary strength is the abstraction that Gilpin notes in his statement. A model that is free of elements peculiar to any specific empirical context is potentially applicable to a variety of these contexts. If our goal is to develop models that can account for the widest possible set of situations, we must formulate these models on a very high level of generality.

There is an important side benefit to the construction of a model designed to be invariant over a significant span of time and space. Since concepts applicable to a 
single era or geographic area cannot be used, the net result is often a simpler model than one that is tailored to fit closely a single domain.

A simple model can also be a "pure" or "ideal" case. Such a model can better illustrate the impact of individual assumptions, as well as the total consequences of the entire set. The more realistic a model, the more complicated it is, and the harder it is to make these determinations. The simpler the model, the better we can understand it and use its insights to account for behavior.

But we purchase the ability to talk about a wide set of cases at the cost of being unable to say as much as we would like about individual cases. This is a large price to pay unless we have some reason to believe that a single model (albeit a very general one) can offer a high level of insight into many different circumstances. Without this assurance, we run the danger of becoming involved in a totally artificial exercise that does not lead to knowledge about international politics.

Fortunately, there is a degree of uniformity in descriptions of state (or city-state) systems, not only in Europe, but in ancient India (Modelski, 1964), Renaissance Italy, the Chou dynasty in China (Holsti, 1977), and even as a possible cause of the Trojan War (Wood, 1985). All these accounts speak of a system with few rules of conduct, forcing states to rely on their own resources and abilities-particularly their power-to survive and prosper.

\section{The Value of Simulation}

Computer simulation allows a researcher to present a model as a series of program statements. This facility permits the researcher to "create" a world that corresponds exactly to her/his model. This flexibility can greatly reduce the difference between one's informal expression of a model and the language used to make it more rigorous and susceptible to evaluation and testing.

A second advantage of this approach is that the computer can serve as a "deduction machine" to display the consequences of the interaction of a set of assumptions after any finite length of simulated time; that is, a simulation is a working model. In an investigation such as this, the main interest is in the emergent properties of a system, and the long-run consequence of these properties for state behavior. This may be very hard to determine using another research approach.

A third advantage of computer simulation is that the researcher is guaranteed that she or he is viewing a closed system. No unprogrammed external factors can intervene to affect the evolution of the system. Whatever the long-run outcome, a researcher can be sure that this was due to some combination of the program and its inputs (of course, determining the exact specification of the causal process may not be trivial or straightforward). A glance back through history shows that in several cases (the Italian city-states during the Renaissance, for example), the "natural" development of the system was disrupted by the entrance of an external power (France). A simulation can allow us to follow the course of "natural evolution" to its logical outcome, which may not be possible with empirical methods.

Finally, judicious use of random elements (i.e., a Monte Carlo simulation) can aid in an investigation. They can be used to introduce necessary but theoretically uninteresting processes in the model, or to help approximate important factors for which an explicit specification is unavailable or impractical. However, a price is paid for the introduction of these elements. First, the simulation must be run a number of times, since any single run may be the result of extreme or atypical values. Second, as 
a consequence of the necessity for multiple runs, conclusions can be formed only in terms of the general, typical, or average behavior of the system. It is not possible to find a deterministic solution.

Given these characteristics, a Monte Carlo computer simulation is an appropriate tool for exploring the long-term consequences of an anarchic international system. It offers a set of strengths that are particularly apt for a theoretical experiment on the interaction between state and system. In the next section, I offer a brief description of the simulation, along with a discussion of the parameters and research design to be used in the exploration.

\section{Simulation, Parameters, and Research Design}

In this section I provide information on the simulation and specify how the theoretical experiment will be conducted. In brief, a set of parameters will be varied, and multiple runs (using different random number seeds) made on each combination of parameters. The output from these runs will then be subjected to statistical analysis to shed light on the research questions.

\section{The Simulation}

In the interest of conserving space, only a brief description of the simulation is included, primarily in the form of an outline. Since no copy of the original version exists, I relied heavily on the extensive discussion in Bremer and Mihalka (1977) in my reconstruction. The reader is urged to consult the original source for a more in-depth discussion. ${ }^{1}$

The simulation is most easily understood as consisting of four segments: an initialization segment that occurs only at the beginning of a run, and a sequence of three segments (opponent selection, war outcome and costs, power adjustment) that can occur in each iteration of the simulation.

I. Initialization segment.

A. Read in parameters for:

1. Mean and standard deviation of power distribution.

2. Standard deviation of power estimation distribution.

3. Standard deviation of war outcome.

4. Seed for random number generator.

5. Maximum number of iterations.

6. Internal growth rate.

B. Set up initial "world."

1. Initialize map to ninety-eight states in seven rows and fourteen columns (see figure 1).

\footnotetext{
${ }^{1}$ I wish to acknowledge the work of Peter Holck, who initiated the coding of the reconstruction. The program is written in the $\mathrm{C}$ programming language, and consists of approximately 2,500 statements. It runs on an IBM-PC, and uses about $52 \mathrm{~K}$ of memory. The program runs with or without an 8087 mathematical coprocessor chip. All runs for this paper were made using a coprocessor. Individual runs took four to five minutes; execution time is about four times longer in an IBM-PC without the chip. A copy of the code has been deposited in the editorial offices of International Studies Quarterly. ISQ will make copies available to other researchers, at the cost of reproduction, upon request. Another reconstruction of the original simulation has been undertaken by Cusack and Zimmer (1986).
} 


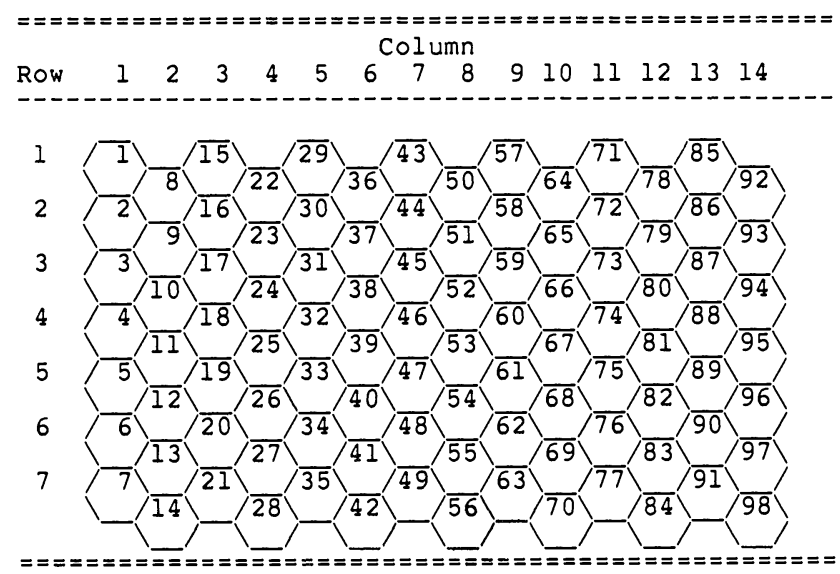

FIG. 1. Initial map for the simulation runs.

2. Using parameters, randomly assign an initial amount of power and an ability to estimate power to each state.

(Segments II through IV may repeat for each iteration.)

II. Opponent selection segment.

A. Randomly select initiator. Chance of a state being selected is equal to its proportion of the total power in the system.

B. Search for a target. Initiator examines all states on its borders, calculates its power advantage over each, and selects the state over which it has the greatest advantage. If it calculates that no surrounding state is weaker, simulation moves to segment IV.

C. Calculate power disparity between target and initiator.

1. If the target is weaker, it seeks allies. All of its allies must border on the initiator state. The combined power of the proposed coalition must provide the smallest possible margin of superiority over the initiator (i.e., it must be a minimal winning coalition).

2. The target sends requests to all states selected as allies. Each potential ally calculates whether the proposed coalition will be larger than the opponent. If so, then it joins the coalition; if not, it does not join.

D. Calculate power balance between initiator and opponent (including any allies of opponent).

1. If initiator is weaker, then it seeks allies using the same procedure as the target (allies must be adjacent to target; proposed coalition must be minimal winning).

2. If the proposed coalition is more powerful than the opponent's, the potential partners join.

3. If the proposed coalition is less powerful than the opponent's, it backs down, and the simulation proceeds to segment IV.

E. Calculate the current power balance between the two sides. If the target is weaker, it goes through another round of alliance-seeking and sends bids. Potential allies make the same type of calculation, and join or refuse to join the coalition. 
F. Calculate the final power balance between the two sides. If the initiator is weaker, it backs down. Otherwise war occurs.

III. War outcome and costs segment.

A. Determine war outcome by multiplying the actual initiating side's power by a random component. If this figure is larger than the target side's power, the initiator wins; otherwise the target wins.

B. Assess all participants a war cost, based on the power ratio between the two sides (the closer the ratio to 1.0, the more costly the war), but subject to a prespecified limit.

C. Assess all states on the losing side an additional war cost of 10 percent of their power. This goes into a "pot" to be divided among the members of the winning side.

D. Use the power ratio between the winning and losing sides to calculate the number of cells of territory to be lost by the leader of the losing coalition. At least one cell is always lost.

E. Distribute to each member of the winning side a share of the loser's "pot" of power equal to the state's proportion of the winning side's total power.

F. Distribute cells given up by the loser to members of the winning side in order of power (i.e., the most powerful state on the winning side gets the first cell, the second most powerful state gets the second cell, etc.)

IV. Power adjustment segment.

A. Eliminate all states with no remaining power or cells of territory.

B. End the run if only one state is left or the iteration limit is reached. Otherwise, grant all remaining states internal power growth of 3 percent. The simulation moves to segment II.

Let me make a few additional points about the simulation. First, in every calculation made by a state (e.g., which side is weaker, whether to join a coalition), its power estimation ability is part of the calculation. Given the size of this value, the calculation may produce an incorrect conclusion. Second, when selecting the cells that the leader of the losing side must give up, a cell must be adjacent to the state gaining the cell, but every attempt is made (a) to select a cell that is on the periphery of the losing state, and (b) not to split up the losing state into several discontinuous areas.

Finally, note that the artificial world created in the simulation is a very primitive one. States make simple, shortsighted evaluations before acting. The world itself has only the minimal elements of the realist environment. But this arrangement has advantages. First, as a general research practice, it is easier to add complications to a simple model than it is to subtract them from a complicated model. Future studies can include a more realistic world and allow for straightforward comparisons with the version presented here. A second advantage concerns the central focus of this paper: balancing behavior in a system of self-interested states. Finding traces of balancing in such a primitive, anarchic world provides a strong basis for concluding that this behavior is likely to exist in a more complicated world, in which states can be plausibly assumed to have an interest in system equilibrium, and the system itself provides some constraints on unbridled self-interest. ${ }^{2}$

\footnotetext{
${ }^{2}$ The original designers of the simulation had to make some judgments about what elements of realpolitik to include, what to exclude, and what level of abstraction to use. For example, the simulation treats the world as having states in the center and states on the periphery, rather than as a globe in which every state has six neighbors
} 
TABLE 1. Parameter specifications for the simulation runs.

\begin{tabular}{lc}
\hline \multicolumn{1}{c}{ Parameter } & \multicolumn{1}{c}{ Value(s) } \\
\hline Maximum number of iterations & 500 \\
Mean for power distribution & 10.00 \\
Standard deviation for power dist. & $3.33,6.67,1.67$ \\
Mean for power estimation & 1.00 \\
Standard deviation for power est. & $0.20,0.40,0.10$ \\
Standard deviation for war outcome & $0.20,0.40,0.10$ \\
Growth rate & 0.03 \\
\hline
\end{tabular}

\section{The Parameters}

As discussed above, when random elements are introduced in a simulation, it is necessary to conduct a number of runs to determine its average behavior. In this paper, a set of values was used for three user-input parameters (see the discussion of segment I above), and each combination of parameter values was run with a number of different seeds for the random number generator. Table 1 displays the parameter values used for the simulation runs reported in this paper.

The parameter for the standard deviation of the initial power distribution was varied to take into account the impact of even and uneven power distributions on the behavior of the system (the smaller the standard deviation, the more even the distribution of power across the original ninety-eight states). This was an important parameter to vary because of the references in the literature to an even distribution of power serving as an aid in maintaining the system in equilibrium.

The parameter for the distribution of power estimation ability was varied to control for the impact of accurate intelligence on system behavior. A number of accounts of the balance of power stress that vigilance and an ability to gauge power accurately can aid the operation of the system (Gulick, 1955). On the other hand, the original work of Bremer and Milhalka (1977) showed that higher levels of inaccuracy (i.e., larger standard deviations) resulted in a lower level of state activity (less alliance-seeking, less alliance-joining, fewer wars) and longer runs before a single state acquired all the territory. This apparent contradiction in the effects of accuracy makes varying this parameter especially important.

Finally, the standard deviation for war outcome was varied to control for the impact of unforeseen factors ("fate," "luck") on the outcome of a war. The larger the standard deviation, the greater the role of chance in determining the winner and loser of a war. Much as with the power estimation parameter, the traditional literature would lead one to expect that the larger the role of chance, the greater the difficulty in maintaining the system. With a large standard deviation, "good decisions" (decisions made by states with a good ability to estimate power) are as likely to be punished as bad decisions.

As displayed in table 1, three different values were used for each parameter. An initial "normal" value was selected, as well as a value one-half the normal value, and a

(i.e., the map "wraps around"). Some may view this as a distortion, but inclusion of this feature allows the assessment of the impact of an abstract geographical feature on state survival (Stoll, 1986) or on the evolution of the system. 
value double the initial value. Each of the resulting twenty-seven parameter combinations was run with ten different start values for the random number generator in the program. The start values were taken from a table of random numbers. $^{3}$

\section{Research Design}

Data from the 270 simulation runs will be used to answer the two questions posed earlier: (a) Does balancing behavior emerge in a primitive, anarchic system? and (b) is this enough to preserve the existence of most states? Since the second question is more easily answered, the discussion of the research design for it will be brief. Several different analyses will be conducted to answer the first question.

\section{System Preservation}

All runs of the simulation had an iteration limit of 500. Support for the ability of a system of self-interested states to preserve itself is inferred if the system deadlocks before iteration 500. A deadlock occurs if the size of the system remains unaltered for an extended period of time; more specifically, a deadlock occurs when the attrition in system membership ceases at some point before the iteration limit. Previous work with a number of variants of this simulation (Bremer and Mihalka, 1977; Cusack and Zimmer, 1986; Stoll, 1986) would indicate that this type of stabilization is a rare occurrence. Any runs that stabilize slightly before the iteration limit are rerun with a larger limit to insure that the apparent stability is not simply a result of the iteration limit, but persists for an extended period of time.

\section{Balancing: Concept, Measurement, and Analysis}

The key behavior of interest in this theoretical experiment is balancing. In the simulation, an iteration begins with the selection of an initiator. This initiator then examines its borders for a target - a state that the initiator calculates it can defeat in a war. Given this situation, balancing behavior is defined as follows: balancing behavior occurs when the power ratio of target to initiator changes to become more favorable to the target, and therefore to decrease the chances of the target losing the war.

Balancing behavior is not programmed into the simulation. To make this point clear, consider the three types of states involved in a conflict: the initiator, the target, and states sought as allies.

The initiator confronts a variety of choices in the course of an iteration: the selection of a target, whether to seek allies, and (at several points) whether to back down or to escalate. At each of these points, the initiator seeks to ensure that it has a power advantage over the target. If it does not have a power advantage, and if it

\footnotetext{
${ }^{3}$ As a precaution, two series of additional runs were done with more extreme values for each of the three parameters. Since the purpose of these runs was to investigate the properties of the model under more extreme conditions, a new set of only upper and lower values was used, and just three runs were made for each set; the result was twenty-four runs for each of the two new series. For the first series, low values of all three parameters were set to 0.05 , the high value for the power distribution was 10 , and the remaining parameters had high values of 1.0. For the second series, low values of all three parameters were set to 0.01 , the high value for the power distribution was set to 20 , and the high values for the remaining parameters were set to 2.0. For important differences between the results for these runs and those discussed in the text, see n. 5 .
} 
cannot create such an advantage, it backs down. The initiator always acts either to create a power advantage for itself or to retreat from a situation in which it is at a disadvantage.

The other two types of state can be considered more briefly. The target has two opportunities to seek allies; in both cases, it attempts to construct a coalition whose power is greater than that of the opponent. States sought as allies estimate whether the proposed coalition will be more powerful than the other side. If the potential ally calculates that it will be on the larger side, it joins the coalition; otherwise it will not.

Each individual state in the system acts in terms of a narrowly defined (and primitively calculated) self-interest. At the heart of this self-interest is the calculation of a power ratio. States always strive to put themselves in a position whereby they are a member of the more powerful side. But despite the lack of individual state behavior motivated by the goal of balancing, the net results at the dyadic level (i.e., at the level of the conflict) may still be balancing behavior. Determining whether this is true in the simulation is the focus of this paper.

Balancing behavior can be traced through the observation of two aspects of the behavior of the simulation. First, if the target puts together a coalition whose power is calculated by the initiator as being larger than its own, the initiator backs down. Thus, if an initiator and a target are selected, but no war occurs, this is evidence of balancing. Second, if the conflict does escalate to war, balancing behavior is observed if the final ratio of target-to-initiator power (the ratio that includes all actual participants in the war) is more favorable to the target than the power ratio between just the target state and the initiator state.

To distinguish between the two aspects of balancing, note their correspondence to the traditional distinction between deterrence and defense. Deterrence involves convincing a potential adversary that the potential costs of undertaking an action outweigh the benefits. In the context of the simulation, an initiator is deterred if it calculates that it is unlikely to win the war. Defense involves defeating an adversary in actual combat. In the simulation, the more favorable the power ratio to the target, the more likely the defeat of the initiator. The first form of balancing (stopping the escalation to war) will be called deterrent balancing, and the second (the occurrence of a war, but with a change in the power ratio favorable to the target) will be called defensive balancing.

Both forms of balancing behavior can be determined in a straightforward manner. The degree of deterrent balancing can be measured by comparing the proportion of conflicts that end in war to 1.0 (the proportion of conflicts we expect to end in war if no balancing occurs). The degree of defensive balancing can be measured by examining all iterations that proceed to war and comparing the initial ratio of target to initiator to the final power ratio (i.e., the ratio incuding all participating allies). If defensive balancing occurs on a regular basis, the final ratio should be consistently more favorable to the target than the initial ratio. ${ }^{4}$

The two comparisons described above provide global assessments of the amount of balancing behavior that emerges from the artificial world of the simulation. But

\footnotetext{
${ }^{4}$ Two additional points should be made about the analysis. First, given the very large number of iterations, we should expect any statistical test to obtain results that are unlikely by chance, even if the results have no substantive import. The second point is that in a "real" balance-of-power system, a variety of means are available to states to increase their available power, and therefore to engage in balancing (see Gulick, 1955, for an especially lucid exposition). However, in this simulation, all attempts to balance boil down to the power ratio between initiator and target.
} 
there are two sets of possible influences that should be examined to determine if any pattern of balancing is unusual, or confounded by a subset of the runs. First, the behavior may shift with changes in parameter values. Balancing may occur under some sets of parameters, but not under others. Second, behavior may shift during the course of a run. Balancing may be present to a different degree in the earlier iterations of a run than in the endgame that occurs when only a few states remain. Several analyses will be presented to control for these effects.

\section{Results and Discussion}

The answer to whether this system of self-interested states can maintain itself is clear: only six of the 270 runs deadlock. The remaining 264 runs end between iteration 177 and iteration 423; the mean is 252.9 iterations, with a standard deviation of 42.6 . Clearly, given this particular world, the ultimate outcome of the interaction of self-interested states is an empire. ${ }^{5}$

\section{Testing for Deterrent Balancing}

The $t$-tests used to evaluate the amount of deterrent balancing in the simulation are displayed in table 2. The table shows conflict iterations (each iteration in which an initiator and a target is selected) aggregated across all runs, and then grouped by iteration. In each line, the distribution of war and no-war outcomes is displayed, along with the probability of a conflict ending in war.

If no balancing occurs, we expect that all conflicts should escalate to war. The $t$-values in the table are calculated assuming 1.0 for the expected proportion of escalations and comparing this to the observed proportion of escalations. The size of the $t$-values for each grouping of iterations (ignoring the small number of cases at iterations 400 and beyond), indicates that a significant number of conflicts do not escalate because the initiator at some point calculates that the power ratio is not advantageous. The chances of a conflict escalating to war drop throughout the iterations, from almost 90 percent (a probability of .82) in the first fifty iterations, through 49 percent for iterations 251-300 (remember that the average number of iterations in a run is just over 250), to 0 for iterations $451-500$.

In sum, there is evidence of deterrent balancing in the simulation. Although war represents the best means for a state to gain power, the proportion of iterations ending in war drops steadily throughout a run. There is even a noticeable deterrent effect in the earliest iterations. All of this behavior occurs even though all states simply calculate whether involvement in a conflict will place them on the more powerful side.

\footnotetext{
${ }^{5}$ Dummy variables were coded for each parameter's high and low values (i.e., for each parameter, one variable was coded 1 when it took on its high value, and 0 otherwise, and a second variable was coded 1 when it took on its low value, and 0 otherwise). Regressing the total number of iterations in a run on this series of dummies produced an $r$-square of only 0.15 , indicating that the parameter values had little impact on the length of a run. The average number of iterations in the two extreme value series of runs (see n. 3) was 295.7, and 10 of these 48 runs (21 percent) deadlocked. Regressing the length of a run on dummy variables for the parameter values revealed that the war outcome parameter had the largest impact on the length of a run. The effect of an extremely large random component is to reduce, perhaps even destroy, the relationship between power advantage and victory. If winning a war is random with respect to power, it will be much more difficult for states to continually accumulate power by fighting weaker opponents, since they will lose some of these wars. The consequence of this is to lengthen the period of time until a single state controls the map.
} 
TABLE 2. Testing deterrent balancing: $t$-values for proportion of conflicts escalating to war (expected proportion of escalations: 1.0)

\begin{tabular}{lcccc}
\hline \multicolumn{5}{c}{$\begin{array}{c}\text { Outcome of } \\
\text { conflict }\end{array}$} \\
\cline { 3 - 4 } Iterations & $\mathrm{t}$-Value & No war & War & $\begin{array}{c}\text { Probability } \\
\text { of war }\end{array}$ \\
\hline All & -140.4 & 14516 & 40488 & .74 \\
\hline $1-50$ & -49.6 & 2021 & 9223 & .82 \\
$51-100$ & -53.9 & 2321 & 9190 & .80 \\
$101-150$ & -57.8 & 2578 & 8730 & .77 \\
$151-200$ & -61.7 & 2802 & 7772 & .74 \\
$201-250$ & -61.7 & 2454 & 4444 & .64 \\
$251-300$ & -49.9 & 1118 & 909 & .49 \\
$301-350$ & -49.6 & 560 & 165 & .23 \\
$351-400$ & -47.2 & 283 & 41 & .13 \\
$401-450$ & -52.5 & 190 & 14 & .07 \\
$451-500$ & - & 189 & 0 & .00 \\
\hline
\end{tabular}

\section{Testing for Defensive Balancing}

As discussed earlier, even if an initiator escalates a conflict to war, the balancing tendencies of the system may result in a diminished power advantage for the initiator, and consequently a greater chance for the target to survive. This type of balancing is measured by comparing the power ratio of the target state to the initiator state, with the final target-side to initiator-side ratio (which involves all of the allies that have joined either side). The results of a series of $t$-tests, one on the entire set of conflicts ending in war, and then a series of tests for groups of iterations, are shown in table 3 .

Examining first the $t$-test for all observations (at the top of table 3), we can see that there is a large difference between the first and final power ratios (note: the reader

TABLE 3. Testing defensive balancing: $t$-values for change in target-to-initiator power ratio

\begin{tabular}{lcccr}
\hline Iterations & $\mathrm{t}$-Value & Start ratio & End ratio & \multicolumn{1}{c}{$N$} \\
\hline All & 139.5 & .51 & .81 & 40489 \\
\hline $1-50$ & 78.1 & .58 & .94 & 9575 \\
$51-100$ & 76.6 & .52 & .89 & 9199 \\
$101-150$ & 68.0 & .47 & .81 & 8708 \\
$151-200$ & 53.1 & .45 & .74 & 7699 \\
$201-250$ & 29.9 & .50 & .67 & 4253 \\
$251-300$ & 8.9 & .60 & .69 & 841 \\
$301-350$ & 0.4 & .62 & .69 & 161 \\
$351-400$ & 1.0 & .59 & .72 & 40 \\
$401-450$ & 0.0 & .71 & .71 & 13 \\
$451-500$ & - & .59 & - & 0 \\
\hline
\end{tabular}


should bear in mind that this $t$-test had 40,489 observations, so any difference in ratios will be statistically significant). The initial ratio (.51) gives the initiator almost a $2: 1$ advantage, but this is decreased to $1.2: 1$ if a war is fought.

Turning to the separate tests for each group of iterations, we see that the defensive balancing effect declines through time. This is seen most readily in the fall of the $t$-value from 78.12 for observations in iterations $1-50$, to very small values for iteration 300 and beyond (remembering that very few runs go beyond the 300th iteration). Note that the start ratio-the ratio between the target state and the initiator state-remains close to .5 for the first 250 iterations. What changes is the end ratio, the ratio including all allies, which declines through time.

\section{Parameter Value Effects}

Since the effect of time on balancing behavior has been examined in tables 2 and 3 , it is only necessary to explore the impact of parameter values. The effects are displayed in table 4. For each extreme parameter value (i.e., the high value and the low value, but not the normal value), a dichotomous variable was created, classifying iterations as either having the value, or not. The result of this procedure was to place about one-third of the observations in the "have" category, and the remainder in the "have not" for each parameter.

The top of table 4 displays, for each dichotomous variable, the proportion of iterations ending in war and no war. A $t$-value for the difference in proportion is also displayed. Bearing in mind the earlier caution about inferring too much from the $t$-values, considering the large number of observations that go into each calculation, there is little difference in the amount of deterrent balancing by parameter value. The largest difference occurs for the power estimation standard deviation, indicating that the larger the standard deviation (and hence the greater variability in estimation ability across states), the more the amount of deterrent balancing. As with the initial simulation study of Bremer and Mihalka (1977), a world of varying estimation ability produces "cautious" behavior by initiators.

The bottom of table 4 displays the difference in first-to-final target-to-initiator power ratio by parameter value. In other words, in the runs with the high value for the standard deviation of power estimation, the power ratio of target to initiator shifted an average of .34 from the first to the final (i.e., including all allies) ratio, while the power ratio for all runs without the high value on this parameter shifted an average of .30 . As with deterrent balancing, the power estimation parameter is the only one that has any impact on balancing behavior.

\section{Summary of Results}

The results of the analysis are clear. In this anarchic, self-help system, even though there is no incentive or imperative for states to behave to restrain the aggressive actions of others, there is a tendency for balancing behavior to emerge. If this is the good news, the bad news is that although balancing behavior occurs in the very primitive world of this simulation, this is an insufficient guarantee for system preservation. In all but a handful of runs, one state emerges as the sole survivor of the ninety-eight-state system. 
TABLE 4. Testing for parameter value effects: $t$-values for deterrent and defensive balancing

\begin{tabular}{|c|c|c|c|}
\hline \multirow[b]{2}{*}{ Parameter } & \multicolumn{2}{|c|}{$\begin{array}{c}\text { Value } \\
\text { present? }\end{array}$} & \multirow[b]{2}{*}{$\mathrm{t}-$ Value } \\
\hline & No & Yes & \\
\hline \multicolumn{4}{|l|}{$\begin{array}{l}\text { Deterrent balancing: } \\
\text { proportion of conflicts } \\
\text { escalating to war }\end{array}$} \\
\hline $\begin{array}{l}\text { High std. dev. } \\
\text { power dist. }\end{array}$ & .73 & .74 & 2.87 \\
\hline $\begin{array}{l}\text { Low std. dev. } \\
\text { power dist. }\end{array}$ & .74 & .73 & 1.35 \\
\hline $\begin{array}{l}\text { High std. dev. } \\
\text { power est. dist. }\end{array}$ & .71 & .79 & 18.82 \\
\hline $\begin{array}{l}\text { Low std. dev. } \\
\text { power est. dist. }\end{array}$ & .77 & .68 & 21.00 \\
\hline $\begin{array}{l}\text { High std. dev. } \\
\text { war outcome }\end{array}$ & .73 & .74 & 3.40 \\
\hline $\begin{array}{l}\text { Low std. dev. } \\
\text { war outcome }\end{array}$ & .74 & .72 & 4.38 \\
\hline \multicolumn{4}{|l|}{$\begin{array}{l}\text { Defensive balancing: } \\
\text { change in target-to- } \\
\text { initiator power ratio }\end{array}$} \\
\hline $\begin{array}{l}\text { High std. dev. } \\
\text { power dist. }\end{array}$ & .30 & .34 & 8.29 \\
\hline $\begin{array}{l}\text { Low std. dev. } \\
\text { power dist. }\end{array}$ & .33 & .29 & 8.26 \\
\hline $\begin{array}{l}\text { High std. dev. } \\
\text { power est. dist. }\end{array}$ & .36 & .28 & 30.56 \\
\hline $\begin{array}{l}\text { Low std. dev. } \\
\text { power est. dist. }\end{array}$ & .25 & .42 & 36.27 \\
\hline $\begin{array}{l}\text { High std. dev. } \\
\text { war outcome }\end{array}$ & .32 & .31 & 2.08 \\
\hline $\begin{array}{l}\text { Low std. dev. } \\
\text { war outcome }\end{array}$ & .31 & .31 & 0.19 \\
\hline
\end{tabular}

\section{Summary}

The relationship of state behavior to system behavior has occupied the thoughts and words of many international scholars. Most authors have asserted that while self-interest is the dominant (even proper) motivation of states, this is not sufficient to keep the system in equilibrium. However, there is considerable disagreement as to what is necessary to prevent the system from disintegrating.

In this paper, I introduced a tool to perform "theoretical experiments" on anarchic systems: a computer simulation. I used the simulation to investigate whether balancing behavior would emerge in a very primitive environment consisting of shortsighted but expansionist states. Perhaps surprisingly, it does emerge, however this is not enough to keep one state from dominating the system.

Given the very primitive world of the simulation, it may be better to focus on the 
existence of balancing behavior, rather than the final outcome. This behavior leads one to speculate that in a less primitive environment containing states with more foresight, and perhaps some constraints on state behavior, self-interested balancing might well preserve the system.

Examination of this speculation must be deferred for future research. For now, we must conclude only that balancing can emerge in even the most primitive environments, and that a computer simulation is an attractive way to explore the theoretical possibilities in the power politics and balance-of-power literatures.

\section{References}

Axelrod, R. (1984) The Evolution of Cooperation. New York: Basic Books.

Bremer, S. and M. Minalka. (1977) Machiavelli in Machina: Or Politics among Hexagons. In Problems of World Modeling, edited by K. W. Deutsch et al., pp. 303-37. Boston: Ballinger.

Bueno de Mesquita, B. (1981) The War Trap. New Haven: Yale University Press.

Claude, I. (1962) Power and International Relations. New York: Random House.

Crowe, E. (1929) England's Foreign Policy. Reprinted in Politics and the International System, edited by R. Pfaltzgraff. Philadelphia: J. B. Lippincott, 1971.

Cusack, T. and U. Zimmer. (1986) The Bases of Multistate System Endurance. Paper presented at the Annual Convention of the International Studies Association, Anaheim, Calif., March 25-29.

Deutsch, K. And J. D. Singer. (1964) Multipolar Power Systems and International Stability. World Politics 16: 390-406.

Gilpin, R. (1981) War and Change in World Politics. Cambridge: Cambridge University Press.

Gulick, E. (1955) Europe's Classical Balance of Power System. Ithaca: Cornell University Press.

HaAs, E. (1953) The Balance of Power: Prescription, Concept, or Propaganda? World Politics 5: 442-77.

Holsti, K. (1977) International Politics: A Framework for Analysis. 3d ed. Englewood Cliffs: PrenticeHall.

KaPlan, M. (1957) System and Process in International Politics. New York: John Wiley.

Machiavelli, N. (1940) The Prince and The Discourses. New York: Random House.

Modelski, G. (1964) Kautilya: Foreign Policy and International System in the Ancient Hindu World. American Political Science Review 58: 549-60.

Morganthau, H., revised by K. Thompson. (1985) Politics among Nations. 6th ed. New York: Knopf.

Singer, J. D., S. Bremer, And J. STuckey. (1972) Capability Distribution, Uncertainty, and Major Power War, 1820-1965. In Peace, War, and Numbers, edited by B. Russett, pp. 19-48. Beverly Hills: Sage.

Stoll, R. J. (1986) National Survival in an Anarchic World: A Computer Simulation. Paper presented at the Annual Convention of the International Studies Association, Anaheim, Calif., March 25-29.

Waltz, K. (1975) Theory of International Relations. In Handbook of Political Science, vol. 8: International Politics, edited by F. Greenstein and N. Polsby, pp. 1-86. Reading: Addison-Wesley. . (1979) Theory of International Politics. Reading: Addison-Wesley.

Wood, M. (1985) In Search of the Trojan War. New York: Facts on File. 